\title{
AC 1998-11: All Lectures are Not Created Equal
}

Marilyn Barger, Hillsborough Community College

Mark Maughmer,

Renata Engel, Pennsylvania State University

Richard Gilbert, 
Session 1675

\title{
Session 1675
}

\section{All Lectures are Not Created Equal}

\author{
Marilyn Barger, Renata Engel, Richard Gilbert, Mark Maughmer \\ FAMU-FSU College of Engineering/The Pennsylvania State University/University of South \\ Florida/The Pennsylvania State University
}

\begin{abstract}
In an educational environment that pressures new faculty to become effective and dynamic teachers there is a tendency to overuse and perhaps misuse the new cadre of information transfer tools as well as the lecture. In undergraduate engineering education lectures are commonly used to promulgate two levels of proficiency: Those that deal with basic skills and those that deal with synthesis of knowledge. These two learning levels are similar in that they must maintain the integrity of the lecture structure, but different in their content, complexity, and commission.

Student success in skill-developing courses is absolutely critical if the metamorphosis from engineering student to the engineering intern is to occur. It is impossible to overestimate the value of these courses. It is also impossible to assure student success in these same courses if they are only lecture-based.

Student success in the design, capstone, and/or integration courses is absolutely critical if the metamorphosis from engineering intern to engineering professional is to occur. It is impossible to overestimate the value of these courses. It is also impossible to assure student success in these same courses unless they include a significant lecture-based component.

This paper will focus on the lecture' s role for delivering material from either of these two extreme learning levels or an intermediate plateau. It will consider how lectures are properly and improperly employed in the various courses within an engineering curriculum. It will also illustrate the companion role that problems and projects play in the student learning experience.

\section{Overview}

There are several real constraints assigned to the task of transforming a college freshman into a proficient engineer. Time, talent, and tender certainly top the list. Even if talent and tender were eliminated, for example, by momentarily considering the best student body at a wellendowed engineering college taught by the best faculty possible, time would still be a formidable issue in itself. An engineering curriculum must use its courses to move its students from potentially algebra illiterate high school graduates through a reasonable introduction of the various engineering disciplines and finally into and ultimately completing the requirements of a selected engineering field. This is to be accomplished in a nominal four year time period in which usually $50 \%$ or more of the student' s courses are not within the engineering domain.
\end{abstract}


The task is accomplished by arranging the engineering courses in a tightly packed interlocked progression that moves the students from an introduction to the basic skills required through proficiency in those skills to final ownership of those skills. In addition, each of these courses is comprised of lectures, problems and projects. Whether the courses are introductory or capstone level, they are lecture driven with problem and/or project components filling in the rest of the learning experience. This three-tier approach is essential for students to develop into practicing engineers who are capable of applying fundamental concepts to the solution of complex problems.

Typically, one thinks of introductory courses as a series of lecture/recitation sessions where the pace of the course is set by the amount and degree of technical material to be covered. By contrast, the capstone design courses, or project-based courses, have a less formal structure with content based on the specific project goals, the knowledge base of the students, and the level of expertise of the instructor. The delivery method can vary from the traditional chalk-and-talk approach to the use of in-class demonstrations or computer simulations; however, the intent is to deliver specific information with which the students can practice.

The majority of practice activities is associated with problems and projects and requires time outside of class. A host of practiced-based tools are available and students can benefit from using a selection of approaches. For example, recitation sessions (often identified with the introductory courses) tend to demonstrate appropriate techniques, particularly with regard to setting up problems. Other methods include the use of CD- ROM or other self-paced tutorials. These are ideal for students to gage their own performance, without the recognition from either kudos or admonishments. Of course, these require student discipline, as the self-paced approach has no intrinsic incentive unless the instructor intervenes with deadlines. Finally, assigned homework problems are another example of strengthening the understanding of concepts.

It is clear that the student' s progress through an engineering discipline' s subject material is synchronized with that engineering curriculum's course progression. It may not be obvious that the lectures associated with that curriculum must also in a sense mature as the student move through those courses. This maturation does not necessarily reflect on a lecturer, the lecturer' $\mathrm{s}$ lecturing ability, or the fact that course content complexity increases later in the curriculum. This maturation refers to the increased complexity in the course goals and objectives and how the course lectures must be adjusted to meet those intentions. It is convenient to explain this change in the lecture in relationship to the curriculum as well as to the courses within that curriculum. 


\section{The Curriculum Perspective}

As suggested above, all engineering curricula tackle the task of preparing their graduates for a successful engineering career by ultimately using a series of courses that follow the same progression. The first courses in the sequence are used for development of basic skills within that discipline. The middle courses develop the proficient use of those skills in controlled but more complex situations, while the capstone type courses complete student ownership of the entire skill set in an open ended but guided environment. The lecture' s role and content characteristics in each of these course groupings are different. Therefor, the lecturer's style in the first and last grouping of courses is distinctively different and should also reflect this change.

\section{Lectures in Basic Skills Courses}

Skill-drill courses have a weighted use of the lecture information transfer technique, repetition exercises, and remediation requirements. A defining characteristic of these courses is the high, but balanced weighting of its repetition and remediation components. In addition, the lecture structure tends to be simple with considerable focus on Arecipes@ and their arrangement in the solution of simple to moderately simple, single -focused situations. Consider the following example.

An early lecture in a statics course must introduce and utilize the free body diagram concept to balance static forces. The "recipe" in this situation is the consistent, systematic application of vectors to define the forces acting on the structure at any point. The instructor will certainly call the three components of a good lecture, i.e., delivery, enthusiasm, and content command into play. The lecturer's delivery will be verbally and visually clear with short sentences, precise definitions, and a specific, repeated vocabulary that is supported by crisp, single-concept visual aids. The classroom enthusiasm is maintained by ample examples of complex structures that can be reduced to simplified representations and analyzed using the freebody approach. The lecturer' s content command will be expressed by the collection of structures selected to illustrate various applications of the "recipes".

In the previous example, student ownership of the free-body diagram approach is not likely to be accomplished with the lecture alone. The lecture on free-body diagrams forges a foundation for the student, but the real learning experience is culminated by the repetition and, where necessary, remediation exercises. Student success can only be guaranteed when the lecture material is enhanced and supported by many well-structured exercises. If the student is to establish ownership of this skill, repetitive skill building activities are necessary. These problems and exercises must also be structured such that student success is frequent and milestones are rewarded.

This symbiotic relationship between repetitive exercises and the "how-to" lecture is ubiquitous to all fundamental skill-development engineering courses. A student learning how to analyze an RLC circuit is identical to a student learning how to analyze forces on a structure. The circuits lecture should be structured the same way and the use of repetitive and remedial exercises is just as important if the student is to be successful. Among basic skill topics that 
should use the same formula of a "how to" lecture with a heavy dose of practice include dynamics, engineering statistics, material and energy balances, and engineering thermodynamics.

\section{Lectures in Capstone Type Courses}

Capstone type courses are easily characterized by the almost complete absence of remedial activity and the dramatic alteration of their lecture component. In most cases, the time and energy students spend on practice activities has been shifted to attacking a discipline encompassing project or small set of demanding problems that emphasize critical discipline related multiple parameter attributes. The concise "how to" lecture with its succinct instructions has vanished. It has been replaced with sage suggestions, expert evaluation and calculated confusion.

The capstone course is an incubator that nourishes novices as they complete their metamorphosis to fledgling engineer. Lectures in such a course assure the success of that transition. As the course progresses, the lectures move the students from a relatively comfortable and satisfying skill manipulator environment to an uncertain almost chaotic realm. This is the constrained chaos of engineering reality.

With the progression of capstone lectures, students are exposed, perhaps painfully at first, to the stark reality that engineering is more than a masterfully manipulated set of complicated calculations that provide a specific solution to the stated problem. Far from that fantasy, these lectures generate a loud wake up call by demanding serious consideration of and answers to questions that relate to the social, environmental and safety impact of their calculated solution. These lectures move ethical issues from the mental back burner where they were occasionally stirred to keep them somewhere within the student's fleeting consciousness to the forbearing and demanding forefront of mental activity. These lectures ask their listeners to actively consider the impact of their calculated conclusions and verbally respond to the lecturers probing but elegantly simple questions;

"Mr/Ms.., what do you think of Y and why do you think that this is the case?".

Capstone course lectures are open-ended but do not wander. They have specific learning objectives but will be student driven to unpredicted closures. They will discuss situations that are bounded by engineering knowledge and logical conclusions but circumscribed by human concerns, superstitions, prejudices, fears, and frailties. They represent classroom experiences for students that far exceed the most abstract philosophy discussion course imaginable because most of the intangible aspects of such a class are present but tempered by the uncompromising reality that a tangible workable conclusion must be secured.

Finally, although the attributes of the "how-to" lecture appear to be flotsam if applied to a capstone course, that is not quite the situation. It is certainly true that there is not time in a senior level course presentation to return to the skill building lecture mode. Although engineering conclusions are always based on human calculations today' s calculations are really 
non-human computations. Therefore, the capstone lectures should also sharpen a student' s reality checking ability by providing students with the "how-to" skill of using recognized engineering "rules of thumb" to keep computer calculated solutions within a rational engineering frame.

Such "rules of thumb" were originally developed to save engineers the drudgery of doing difficult dragged out calculations whenever possible. Today, these same rules will warn an engineer to be cautious of computer concocted conclusions that do not concur with engineering common sense driven "rules of thumb". The capstone lecture is a perfect place to present and practice these pre-tested rules. The lecturer can repeatedly invoke them during lecture lead discussions with the class. The ultimate goal in this case, however, is to instill a cautious rule usage habit into the student's own developing thought, problem solving, and verbalization processes.

\section{The Course Perspective}

At this point, it may be tempting to assume that lectures in basic skill courses differ from their counter parts in the capstone type courses because of the fundamental differences in the two types of courses. This is actually not the case. All courses have a weighted use of lectures, problems and projects. From a curriculum perspective, with no particular course in mind but the overall strategy in focus, there appears to be no global projection for a lecture in a skill-based course. This again is not the case.

For engineering students, the ability to apply the technical knowledge they are learning to relevant problems at their current level of expertise is always a combination of sound fundamental understanding and synthesis of concepts. Rather than teach all fundamentals before embarking on synthesis, a teaching approach that provides an appropriate balance of the two is an effective strategy for demonstrating the importance of each. Thus, in a specific introductory course, the weighted use of lecture, repetition, and remediation activities expands as the course progresses.

As each basic skill associated with an introductory course is presented, the students must have ample opportunity to develop that skill to the level that allows them to participate with confidence in subsequent courses. Until that occurs, the instructor weights repetition and remediation highly and provides sound "how-to" lectures with illustrative exercises to glue these activities together. Before the course moves on to the next skill, however, the current skill's global relevance to the discipline must be introduced. This is accomplished by shifting the lecture focus to an open-ended format that presents a carefully selected set of expansive images to give the students a strong glimpse of the importance of the skill they have just practiced. The instructor reduces the repetition and remediation and increases the lecture' $\mathrm{s}$ engineering application, historical perspectives, social, political, customer needs, and environmental concerns content as needed. Consider an introductory engineering mechanics course as an example. 


\section{Open-Ended Lecture Example in Skill Based Course}

One "how to" objective in an engineering mechanics course is to bring students to a point where the have mastered the skill of determining stresses in the simple components of a structure. With this skill in hand, repetition and remediation activities are temporarily suspended. A parallax to broaden the context of this newly acquired skill is now provided via an open-ended lecture and its complementing design oriented homework assignment.

Students reconsider a problem of a hammock that supports an $85 \mathrm{~kg}$ person at a stated angle between two trees. Previously, they merely analytically determined the stress in the ropes, but this time they are required to submit a written report that considers the ropes as part of the overall function and design of the hammock. No additional information needs to be provided, instead the instructor can guide the students through the process of determining the relevant factors that influence their design. Students will be asked to determine realistic loads (perhaps with the aid of population demographics data) and identify resources from a materials, manufacturing methods and cost perspective. In addition, students will be required to consider alternative markets for their product. (For example, do Huntington's disease patients represent a good therapeutic customer base for the product? If so, what is the impact of rope material, length and tree angle on such an application?)

Naturally, safety factors will be emphasized. Student reports will include proper installation instructions that focus on secure hammock attachment, acceptable securing posts, distance between securing posts, and height from the ground. These guidelines could be in multiple languages to reflect a global customer base. Age usage restrictions and appropriate child warning messages, Consumer Product Safety Commission Document \#5043 (www.kidsource.com/com/SPSC/index.html), will be required. Finally, storage, care and handling techniques for the hammock to insure minimal material wear and fatigue will be stated.

Such extra open-ended lectures and assignments periodically placed in skill-based courses will demonstrate an organized approach to tackling a specific broader problem. The instructor will be able to provide an educational experience that is separate from the technical skill acquisition aim of the course but necessary for the complete development of the student engineer. Engineering faculty often take the development of this thinking skill and level of knowledge synthesis for granted. Perhaps they have forgotten that it has taken years of experience to acquire and become comfortable with these skills. In any event, it is certainly not an activity that can be mastered by students because of one exercise in a single course. Rather, the instructor' s role is to provide this type of lecture as a streamlined experience in a restricted application within the student' s knowledge base and then repeat the experience with each successive basic skill that the student acquires. 


\section{Summary}

All good lectures are created the same way but are not necessarily equal creations. Good lectures have introduction, body and closure sections. They are characterized and manipulated by the lecturer' s use of delivery, enthusiasm and content command, and they effectively deliver an intended message to the listener. For an engineering educator, it is the type of message that segregates good lectures and prevents their indiscriminate use. In some situations, lectures in engineering curricula must narrow the focus of the listener to the specific task of understanding a complicated technical skill. In other circumstances, the lecture must expand the listener' s perspective to appreciate the impact of important but perhaps poorly understood peripheral factors on an intended design. In both cases, these lecture types are fundamentally different and the educator must select the correct type for the right moment in the right course to achieve the optimal education effect.

\section{Bibliography}

Barger, M., R. Engel, R. Gilbert, (1996) "How About a Good Lecture?", American Society of Engineering Education 1996 National Conference Proceedings, Session 1675, Washington D.C.

Barger, M., R. Engel, R. Gilbert, (1997) "A Good Lecture: A Framework for Classroom Management," American Society of Engineering Education 1997 National Conference Proceedings, Session 3230, Milwaukee, WI.

Brookfield, Stephen D., The Skillful Teacher, Jossey-Bass, San Francisco, 1990.

Davidson, M.J., ALecturing with Multimedia Tools, @ Int. J. Engng. Ed., 12:6, pp. 444-456.

Elbe, K. E., The Craft of Teaching, 2nd ed., Jossey-Bass, San Francisco, 1988.

Gappa, Lavon, and B. Gill, Teaching at FSU, FSU Program for Instructional Excellence, Tallahassee, FL, 1991.

Hauser, D. L., E. S. Halsey, J. M. Weinfield, J. C. Fox, "What Works and What Doesn't in Undergraduate Education", ASEE Prism, November 1995.

McKeachie, W. J., Teaching Tips. A Guidebook for the Beginning College Teacher, 8th ed., D.C. Heath, Lexington, MA, 1986.

Wankat, Philip C. and F. S. Oreovicz, Teaching Engineering, McGraw-Hill, Inc., New York, 1993.

\section{Authors}

MARILYN BARGER is an assistant professor in the Civil Engineering Department of the FAMU-FSU College of Engineering where she is developing research programs in waste management, reverse osmosis, and environmental fate and transport. She has a BS in Chemistry from Agnes Scott College and a BS and Ph.D.in Civil Engineering from the University of South Florida. She is a registered professional engineer in Florida and the current chairman of the Environmental Engineering Division of ASEE.

RENATA ENGEL is an associate professor of Engineering Graphics and Engineering Science and Mechanics. She has a BS in Engineering Science from Penn State and Ph.D. in Engineering Mechanics from the University of South Florida. She has developed a research program in composite processing and development and has conducted education research as it relates to instructional software development and implementation. 
Session 1675

RICHARD GILBERT is a professor of Chemical Engineering at the University of South Florida. His interests are focused on sensor and instrumentation development for biomedical, environmental, and process control. For the last 20 years, Dr. Gilbert has presented lectures and short courses throughout the country on various aspects of process instrumentation and control.

MARK MAUGHMER an Associate Professor of Aerospace Engineering, joined the Penn State faculty in 1984. He earned B.S. and Ph.D. degrees from the University of Illinois, and an M.S.E. from Princeton University. His research activities are in the subject areas of aerodynamics, aircraft design, and aircraft stability and control. He is the current chairman of the Aerospace Division of ASEE. 